\title{
Pecuária Familiar: a emergência de uma categoria social no Sul do Brasil ${ }^{1}$
}

\author{
Rafael Gastal Porto ${ }^{2}$ \\ Antônio Jorge Amaral Bezerra ${ }^{3}$ \\ Victor Hugo da Fonseca Porto ${ }^{4}$ \\ Nádia Velleda Caldas ${ }^{5}$
}

Resumo: Este trabalho tem como objetivo identificar e caracterizar a pecuária familiar no município de Bagé, estado do Rio Grande do Sul (RS), segundo alguns critérios (estrutura fundiária, modalidade de exploração, natureza da mão de obra, finalidade da produção, comercialização, intermediários, integração da produção, renda agrícola e renda não-agrícola). Foram realizadas entrevistas diretas a produtores durante os meses de maio e junho de 2007, nas localidades rurais de Palmas, Olhos D'Água, Coxilha do Haedo, Serrilhada e Santa Tecla, totalizando 40 questionários aplicados. A análise de frequência foi utilizada para o tratamento dos dados. A pesquisa apontou que $80 \%$ dos produtores exploram áreas até 200 hectares e que, para 87,5\%, a força de trabalho é exclusivamente de caráter familiar. Quanto à renda agrícola, $70 \%$ dos entrevistados responderam ser inferior a dois salários mínimos. O estudo revelou, ainda, a importância das rendas nãoagrícolas em relação à renda total, particularmente das aposentadorias e pensões, que funcionam como instrumento essencial de reprodução social das famílias.

Palavras-chave: agricultura familiar, bovinos de corte, caracterização.

1 Trabalho elaborado a partir de resultados da Dissertação de Mestrado, de 2008, do primeiro autor pelo Programa de Pós-Graduação em Sistemas de Produção Agrícola Familiar da FAEM/UFPel.

2 Eng. Agrônomo, mestre em Ciências, analista A da Embrapa Clima Temperado. E-mail: rafael.porto@cpact.embrapa.br.

3 Eng. Agrônomo, doutor em Ciências, Professor Adjunto, UFPel, Faculdade de Agronomia, Programa de Pós-Graduação em Sistemas de Produção Agrícola Familiar, Campus Universitário Capão do Leão. E-mail: ajabez@ufpel.edu.br.

4 Economista, mestre em Economia Agrária, Pesquisador Aposentado da Embrapa Transferência de Tecnologia. E-mail: vfonsecaporto@gmail.com.

5 Socióloga, doutoranda do Programa de Pós-Graduação em Sistemas de Produção Agrícola Familiar/UFPel, Bolsista do CNPq e Capes (Doutorado Sanduíche). E-mail: velleda.nadia@gmail.com. 


\begin{abstract}
The objective of this paper was to identify and characterize farm family livestock in Bagé, Rio Grande do Sul State (Brazil), according to some criteria (land area, exploitation of approach, labour use, production objective, commercialization, intermediary, production integration, rural income and no-rural income). Direct interviews were conducted with family livestock farmers during May and June 2007 in the following locations: Palmas, Olhos D'Água, Coxilha do Haedo, Serrilhada and Santa Tecla, comprising a total of 40 interviews. Frequency analysis was used to examine the data. The research showed that $80 \%$ of the farmers explore areas of up to 200 hectares and 87,5\% of the interviewees use exclusively family labour. As for the rural income, $70 \%$ of the cases earned less than two minimum wages. The results also showed the importance of off-farm income compared to total income, particularly from retirements and pensions, which are an essential instrument of social reproduction for the families.
\end{abstract}

Key-words: family farming, beef cattle, characterization.

Classificação JEL: Q12.

\title{
1. Introdução
}

Entre os principais indicadores agropecuários do estado do Rio Grande do Sul (RS) está o fato de $45 \%$ de seu Produto Interno Bruto (PIB) estar vinculado ao setor primário da economia. A pecuária ocupa ao redor de 16 milhões de hectares, representando $56 \%$ da área total do estado (Secretaria de Agricultura, Pecuária e Agronegócio/RS, 2006). Segundo o Instituto Brasileiro de Geografia e Estatística (IBGE, 2007), o rebanho gaúcho de bovinos soma 14.239.906 cabeças, participando com $6,87 \%$ do nacional. O rebanho de ovinos, por sua vez, corresponde a 3.732.917 cabeças ou $24 \%$ do brasileiro. A exploração pecuária no Rio Grande do Sul, de forma geral, é desenvolvida basicamente pelo pastoreio contínuo de campos nativos e também cultivados.

Segundo Miguel et al. (2006), apesar da importância da atividade pecuária extensiva (bovina e ovina), a região da Campanha Meridional gaúcha ainda é marcada por um fraco dinamismo econômico e demográfico. A pecuária de corte no Rio Grande do Sul tem suas origens nos primórdios da ocupação do espaço agrário gaúcho. Fundamental para a formação da sociedade local, tanto do ponto de vista econômico quanto social, hoje essa atividade vive um período de incertezas e pressão por transformações advindas da globalização das economias e dos mercados.

Presente em praticamente todas as regiões do RS e compondo sistemas de produção com as mais diversas formatações (tanto relativamente à sua articulação com as demais atividades agrícolas quanto à sua importância no interior dos sistemas produtivos), a pecuária de corte gaúcha apresenta uma 
realidade diversificada, complexa e, paradoxalmente, pouco conhecida. Se de um lado, constata-se uma relativa profusão de estudos e pesquisas sobre a cadeia produtiva da carne bovina, ressente-se da falta de informações acerca do perfil e da situação socioeconômica dos produtores rurais envolvidos com a atividade. Esse relativo desconhecimento de certa forma preocupa, dada a heterogeneidade de situações encontradas entre os pecuaristas gaúchos.

A aludida heterogeneidade resulta não somente do nível tecnológico adotado pelos produtores e da diversidade dos sistemas de produção, mas, inclusive, da natureza das relações de produção implicadas. O presente estudo parte do pressuposto de que a pecuária familiar representa um segmento peculiar e relevante no âmbito da pecuária extensiva, a qual vem sendo reconhecida por estudos que estimam esse contingente em $12 \%$ do universo da pecuária no RS (Sebrae/Farsul/Senar, 2005). O objetivo deste trabalho é caracterizar a pecuária familiar no município de Bagé, com base em alguns critérios de avaliação, quais sejam: estrutura fundiária, modalidade de exploração, natureza da mão de obra, objetivo da produção, comercialização, intermediários, integração da produção, renda agrícola e renda não-agrícola.

\section{Caracterização da região}

O Rio Grande do Sul, tradicionalmente, apresenta-se como um estado que se destaca pela sua produção agrícola e pecuária. Segundo o IBGE (2007), nos últimos anos, o setor agropecuário (produção) teve participação média de 15,9\% no PIB do estado gaúcho. Sabe-se, contudo, que esse percentual é ainda maior se considerada a repercussão que o setor movimenta nas cadeias produtivas em termos de capilaridade. Na estrutura do Valor Bruto da Produção Agropecuária (VBPA), destacam-se as lavouras, que respondem por $61,34 \%$ da produção, seguida pela produção animal, com 33,98\%.

A estrutura fundiária do RS se diferencia de acordo com a região, alternando predomínio de grandes e médias unidades de produção ${ }^{6}$ com médias e pequenas.

6 Para fins deste trabalho, considerar-se-á "unidade de produção" como sinônimo de "estabelecimento agropecuário". Segundo o IBGE, estabelecimento agropecuário é toda unidade produtiva dedicada, total ou parcialmente, a atividades agropecuárias, florestais e aquícolas, subordinada a uma única administração: a do produtor ou a do administrador; independente de seu tamanho, sua forma jurídica ou de sua localização em área urbana ou rural, tendo como objetivo a produção para subsistência e/ou para venda. Portanto, para essa investigação será considerada a "unidade de produção", seja o produtor proprietário ou não da área (parceiro, arrendatário, posseiro, meeiro, etc.) sem fazer distinção, a priori. A verificação a campo é que dará conta desse aspecto, baseado na realidade dos produtores através do levantamento dos dados e posterior análise dos resultados. 
Pela Figura 1, observa-se que, do total das unidades de produção do estado, 85,71\% possuem menos de 50 hectares, ocupando $24,36 \%$ da área utilizada pela produção agrícola. As unidades de produção com mais de 500 hectares representam 1,83\% do total, representando $41,66 \%$ da área rural. Aquelas compreendidas entre 50 e 500 ha representam $12,46 \%$ do número de unidades de produção, ocupando 33,98\% da área (Secretaria de Planejamento e Gestão/RS, Atlas Socioeconômico do RS, 2006).

$\mathrm{Na}$ Campanha Gaúcha - região de verões quentes e invernos rigorosos, com baixas altitudes comparativamente ao restante do estado-, predominam os campos (pampa). A presença desses campos está mais relacionada à profundidade em que se encontra o lençol freático do que a um determinado tipo de clima ou solo. Estão, também, condicionados ao relevo, que geralmente é suave. A cobertura vegetal predominante é a pastagem natural (nativa), que se apresenta numa variedade de gramíneas e leguminosas, em forma quase contínua ou em tufos. Marcada pela riqueza do solo, conhecido como brunizens, oriundo da decomposição de rochas sedimentares e ígneas, essa região possibilita o desenvolvimento da agricultura e da pecuária. É notável, também, a presença de coxilhas (colinas arredondadas) e das matas galerias nas margens dos rios.

Figura 1. Estrutura fundiária no RS

$\%$

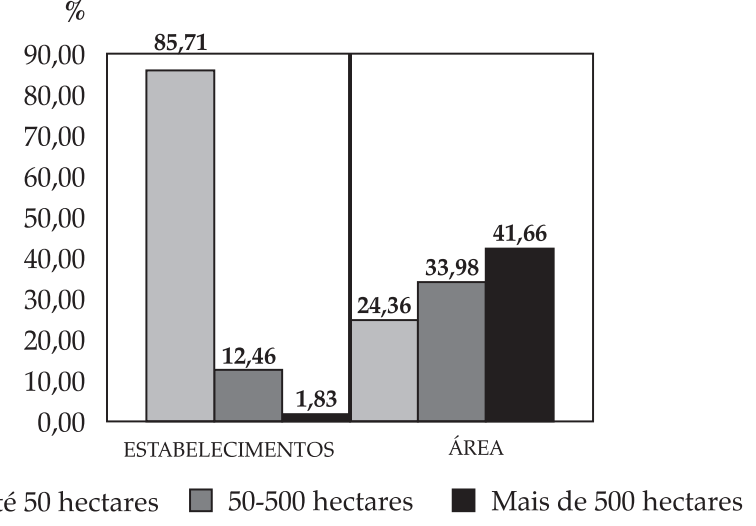

Fonte: SPG/RS, Atlas Socioeconômico do RS (2006).

O município de Bagé está situado na bacia do Alto Camaquã, na mesorregião Sudoeste Rio-Grandense e na microrregião Campanha Meridional, ocupando uma área de $4.096 \mathrm{~km}^{2}$. Seus limites são: a norte, os municípios de Lavras do Sul e Caçapava do Sul; a leste, Pinheiro Machado, Hulha Negra e Candiota; a oeste, o município de Dom Pedrito; e, a sul, a República Oriental do Uruguai e o município de Aceguá. Bagé fica distante $374 \mathrm{~km}$ da capital Porto Alegre. Situado a 218 metros de altitude, o município apresenta clima temperado 
e caracteriza-se por ser essencialmente de produção agropecuária, com a bovinocultura de corte, bovinocultura de leite, ovinocultura, caprinocultura, equinocultura e lavouras de arroz e soja sendo as suas principais explorações. Conta, também, com áreas cultivadas com milho, sorgo, espécies florestais, fruticultura e hortigranjeiros.

Dessa forma, o que se mostra de fundamental importância neste trabalho é verificar características da pecuária familiar no locus empírico de pesquisa, bem como identificar suas peculiaridades em função de condicionantes estruturais e conjunturais. Paralelamente, é feito um resgate teórico para se entender a dinâmica de produção e a realidade da região estudada.

\section{Revisão de literatura}

Para Kautsky (1998), o processo de expansão do capitalismo no campo, consubstanciado na modernização da produção agrícola, provocou profundas e irreversíveis transformações na organização dos espaços agrários, gerando novas formas de expressão da agricultura. No âmago dessas questões, o autor trabalha e questiona a vertente da dialética enquanto campo de transformações sociais e suas formas de representação. Os resultados do processo histórico de modernização da agricultura mostram que a questão agrária sofreu com as opções políticas e econômicas de desenvolvimento adotadas.

Segundo o autor, a grande unidade de produção leva vantagens sobre a pequena em termos, por exemplo, de crédito e transporte, mas, por outro lado, apresenta desvantagens em relação ao pagamento de trabalhadores braçais e intelectuais. O principal obstáculo a manutenção e avanço da grande unidade de produção consistiria no fato de tal processo depender da disponibilidade de terras contínuas e, portanto, apresentaria limites naturais intransponíveis e, por isso, não concorda com a tese da concentração de renda pelo avanço da grande unidade de produção capitalista.

Kautsky enfatiza a utilização de máquinas agrícolas e seu papel transformador, ao substituir a força de trabalho humana e estimular o fluxo de operários agrícolas para as cidades no processo de expropriação do camponês. Essa mudança estrutural da agricultura sob o capitalismo seria comandada pela dinâmica do progresso tecnológico, especialmente devido aos efeitos da agroquímica, a qual acabaria por transformá-la em um ramo da indústria, não eliminando, necessariamente, as pequenas unidades de produção, mas transformando-as em uma forma de trabalho acessório.

O modo de produção capitalista não é a única forma de produção existente na sociedade atual; ao lado destes podem ser encontrados ainda os remanescentes, até hoje conservados, de outros modos de produção pré-capitalistas; também já se manifestam, igualmente, os 
germes de um novo modo superior de produção, em várias formas de economia estatal e comunal, assim como as cooperativas (KAUTSKY, 1998, p. 33).

Em resumo, pode-se dizer que a obra de Kautsky analisa, fundamentalmente, a concepção marxista de superação técnica da grande produção sobre a pequena, bem como, o crescente empobrecimento e proletarização do pequeno camponês, sob a égide do capitalismo.

Chayanov (1974), por sua vez, não acreditava na extinção da produção camponesa, e, sim, na sua persistência. Para o autor, a unidade de produção familiar na agricultura seria regida por princípios gerais de funcionamento internos que a tornariam diferente da unidade de produção capitalista. Ou seja, sem se organizar sobre a base de extração e apropriação do trabalho alheio (maisvalia), mas sim na relação entre o consumo e o trabalho familiar, que engendra consumo e produção sob a responsabilidade do grupo doméstico, respeitando uma lógica e uma racionalidade próprias desse modo de representação. Para Chayanov (1981), o camponês não tende a exceder a exploração da sua força de trabalho para além das necessidades que lhe impõem a sua produção e reprodução. Em outras palavras, o camponês não tem por objetivo maximizar renda, mas sim satisfazer suas necessidades, tendo como traço distinto a capacidade das famílias de imporem a si mesmas um ritmo de autoexploração.

Chayanov afirma que a unidade econômica familiar é vista como uma categoria social que preserva sua existência em pleno mundo capitalista, inclusive, fazendo uso do progresso técnico quando os imperativos forem determinados pela lógica da organização da produção da própria unidade. Dessa forma, não há resposta somente à maximização e à busca do lucro e, sim, uma reprodução social de um modo particular de produção.

Segundo Chayanov (1981), para se conhecer a organização interna da família, é preciso compreender o ciclo familiar completo e como a família realiza o balanço entre necessidade de consumo e o grau de intensidade de trabalho. Somente dessa forma, é possível identificar a lógica que permeia a organização do trabalho e da produção no interior da família. Embora as unidades familiares de produção apresentem traços coerentes com a lógica do capital, distinguir-seiam das empresas capitalistas propriamente ditas pela sua dinâmica própria de funcionamento. A maior aspiração do camponês seria ter terra suficiente para fazer pleno uso da força de trabalho da família. Em outras palavras, a posse ou acesso à terra seria condição indispensável para distribuir, de forma equilibrada, a mão de obra familiar disponível.

Sendo a família, na agricultura camponesa, o elemento-chave para explicar o processo de tomada de decisão, o camponês executaria um balanço (subjetivo) no qual definiria o grau de autoexploração, relacionado ao volume da atividade agrícola e à intensidade do trabalho aos quais a família iria se submeter para satisfazer a relação consumo/trabalho. 
Segundo Ploeg (1992), um aspecto que influencia o processo de trabalho, que não é a coordenação desse processo pela unidade familiar, é o progresso técnico. Com ele, tem-se um aumento do processo de externalização das atividades, antes realizadas na unidade doméstica e que passam a ser desenvolvidas por agentes externos. Esse grau de mercantilização pode variar consideravelmente em relação ao processo de trabalho e produção - vai depender de os meios de reprodução estarem ou não mercantilizados. Quanto mais dependente do mercado for esse processo de reprodução de uma unidade de produção agropecuária, maior será o grau de mercantilização.

Nesse sentido, a análise de Lamarche (1993) quanto à exploração familiar desenvolve-se sobre um eixo hipotético definido pelo grau de integração na economia de mercado. Dessa forma, dependendo do grau de integração com o mercado, há uma determinada relação com a sociedade de consumo, um determinado modo de vida, de representação e de manifestação. As extremidades desse eixo seriam representadas pela exploração camponesa ou Modelo Original e pela exploração familiar ou Modelo Ideal. A localização no referido eixo das explorações familiares dependeria de sua própria história e do ambiente específico no qual elas funcionam, bem como, da forma e do grau de inserção nesse ambiente. Isto é, os exploradores familiares organizam suas estratégias, vivem suas lutas e fazem alianças em função da memória que guardam de sua história e de suas ambições para o futuro.

Nos países industrializados, conforme Lamarche (1993), muitos dos exploradores familiares desapareceram porque não puderam, quando foi preciso, modificar seu sistema de produção e adaptar-se às novas exigências de mercado, sem dúvida por serem muito dependentes do seu Modelo Original. Atualmente, alguns exploradores familiares estão em dificuldades, se diria, até, em processo de falência, por não serem mais capazes de pensar de outra maneira seu modo de produzir e viver; são os exploradores familiares que se encontram desprovidos de praticamente todo seu patrimônio sociocultural, seja porque o renegaram, em todo ou em parte, seja porque seus pais, por diversas razões, não julgaram oportuno transmitir-lhes tais valores. Ao perder esse patrimônio, eles perdem também um capital de conhecimentos através dos quais poderiam encontrar soluções alternativas. Portanto, segundo Lamarche, pode-se formular a hipótese de que, nas sociedades dominadas pela economia de mercado, quanto mais a exploração familiar estiver próxima dos modelos extremos, menos ela poderá acomodar as restrições que se apresentam a essas sociedades e, por isso, mais dificuldades terá de assegurar sua reprodução e existência.

Referenciando o Convênio FAO/Incra, pode-se definir a agricultura familiar a partir de três características centrais:

... (a) a gestão da unidade produtiva e os investimentos nela realizados são feitos por indivíduos que mantêm entre si laços de sangue ou de casamento; (b) a maior parte do trabalho é igualmente fornecida pelos 
membros da família; e (c) a propriedade dos meios de produção, embora nem sempre da terra, pertence à família e é em seu interior que se realiza sua transmissão em caso de falecimento ou de aposentadoria dos responsáveis pela unidade produtiva (FAO/INCRA, 1996, p. 4).

Afirma-se que, na mesma linha de raciocínio, a abordagem de Gasson e Errington (1993) ${ }^{7}$ é a que será utilizada para fins deste trabalho, na qual o conceito de agricultura familiar adotado e estabelecido abrange os seguintes aspectos:

... os traços essenciais da agricultura familiar são: (a) a gestão é feita pelos proprietários; (b) os responsáveis pelo empreendimento estão ligados entre si por laços de parentesco; (c) o trabalho é fundamentalmente familiar; (d) o patrimônio pertence à família; (e) o patrimônio e os ativos são objeto de transferência intergeracional no interior da família; e (f) os membros da família vivem na unidade produtiva (GASSON e ERRINGTON, 1993).

A agricultura familiar, enquanto diversidade de sistemas, deve integrarse e adaptar-se para ter condições de suportar as tensões, como grupo social, causadas entre o que se pode e o que se deseja ser, e o que a sociedade cobra de seus comportamentos. Portanto, integração e adaptação são exigências para a realização das "agriculturas familiares". Se as estruturas produtivas das agriculturas familiares fecham-se sobre si mesmas, torna-se impossível o desenvolvimento de capacidades produtivas por falta de insumos, aqueles os quais não são capazes de produzirem; por outro lado, se o desenvolvimento dessas capacidades põe-se em função exclusiva da dinâmica do mercado, certamente se divorciarão das necessidades sociais e perderão suas próprias razões de serem, suas identidades próprias. Por esse motivo, o lucro não é a lógica das produções familiares, mas uma componente dessa lógica, uma vez que se torna necessário encontrar para suas continuadas existências, enquanto agriculturas familiares, um ponto de convergência entre o atendimento das necessidades sociais sem, no entanto, descuidarem-se da rentabilidade de suas atividades produtivas.

A agricultura familiar, a exemplo da agricultura capitalista, responde aos estímulos provocados pela ciência e tecnologia, isto é, são receptivas e adotam práticas agrícolas inovadoras, umas mais que outras, dependendo das ambiências interna e externa. Entretanto, essa vontade em inovar, por parte do agricultor familiar, devido a movimentos de preservação e conscientização da sociedade em seu entorno, e também a sua, está percebendo com mais clareza que perder seu patrimônio sociocultural e permitir a degradação da ambiência

7 Gasson e Errington (1993) apud Sacco dos Anjos (2003, p. 43). 
natural, pela aceleração vertiginosa da revolução pós-moderna, é um risco que o triunfo total da ciência apresenta e, que inclusive, pode resultar na total desaparição da agricultura familiar.

Conforme Wanderley (1999), o que caracterizaria a unidade de produção familiar camponesa é o sistema policultura-pecuária. Vislumbram-se, ainda nesse aspecto, algumas características mais subliminares desse sistema de produção, que seriam as forças produtivas não-transferíveis e o tempo de não-trabalho desse agricultor. A autora perspectiva a noção do horizonte das gerações no que se refere ao processo de transmissão da terra, bem como outras dimensões que complementariam essas peculiaridades, como a questão da valorização de um meio natural e a ideia de núcleo de habitação dessas unidades de produção familiar. Adiante, Wanderley faz referência às formas modernas de agricultura familiar inseridas no contexto dos mercados e agroindústrias, em que se percebe uma racionalidade própria desses agricultores, alocados em realidades distintas de outros grupos. Ela considera que a agricultura familiar necessita de níveis "mínimos vitais" para que as fragilidades do sistema não venham a desestabilizar essa forma de produção. Nesse particular, a ameaça à autonomia e à precariedade são elementos a serem analisados, pois os processos migratórios estariam envolvidos em dois aspectos básicos: a esperança e o fracasso.

$\mathrm{Na}$ esfera da produção e reprodução, o produtor precisa coordenar suas tarefas, traçando, assim, diversas estratégias para a organização do processo de trabalho e o desenvolvimento da produção agropecuária. Além dessa coordenação de tarefas com relação à organização do processo de trabalho, o produtor terá ainda que coordenar o domínio da esfera familiar com o sistema econômico institucional mais amplo. Segundo Sandrini (2005), esse é o caso dos pecuaristas familiares que, além de decidir quanto ao processo de trabalho na unidade de produção, terão que definir as relações socioeconômicas a serem mantidas fora da esfera da unidade de produção - entre elas, as relacionadas ao processo de compra de insumo, venda da produção, participação em associação/cooperativa, necessidade de empréstimos, etc.

Os conceitos de heterogeneidade e graus de mercantilização são extremamente importantes para o estudo da pecuária familiar. Por meio desse enfoque, pode-se obter um auxílio no entendimento do caráter heterogêneo existente entre os pecuaristas. Algumas unidades de produção possuem alto grau de mercantilização, enquanto outras da mesma região apresentam grau de mercantilização menor (SANDRINI, 2005).

Uma constatação que contraria o senso comum é o envolvimento de um enorme contingente de agricultores familiares dedicados à pecuária de corte. Em 1985, 68\% das unidades de produção rural no País, cuja atividade principal era a pecuária, tinham menos de 50 hectares, apesar de deterem apenas 16,7\% do rebanho. No outro extremo, as unidades de produção superiores a 500 hectares detinham $66,49 \%$ da área, representavam 3,66\% do universo destas 
dedicadas à pecuária e possuíam $45,6 \%$ do rebanho. Isso evidencia que não é, necessariamente, verdadeira a identidade que se estabelece entre a pecuária e as grandes unidades de produção, apesar de caber a estas a maior parcela pelo abastecimento de carne no mercado. Outra constatação é a de que, partindo de uma pecuária praticada em moldes extensivos por todo o País, as inovações tomaram trajetórias diferentes e, às vezes, complementares entre as diferentes regiões. No RS, é mais frequente a produção em ciclo completo, e as inovações basearam-se no cultivo de pastagens forrageiras, principalmente de inverno para apascentamento a campo. Já em São Paulo, as inovações mais expressivas dizem respeito à terminação dos animais em regime de confinamento, utilizando-se subprodutos industriais e culturas vegetais, como cana-de-açúcar, milho, capineiras, etc. Mesmo nas regióes do Centro-Oeste, os melhoramentos na capacidade de suporte das pastagens são diferentes em termos de requisito de investimento e manejo fito-zootécnico em relação àqueles possíveis no RS (MIELITZ NETTO, 1994).

Para se analisar a diversidade de formas de reprodução social dos pecuaristas familiares, é necessário que se tenha uma visão global dos entornos social, cultural e ambiental nos quais os mesmos encontram-se inseridos. Grande parte das pesquisas, ao analisarem as unidades familiares, centra atenção em questões relativas à produção. Ou seja, esquece-se que essa unidade, além de ser produtora de bens primários, é, antes de tudo, o núcleo de uma família. Como ressalta Champagne:

(...) haveria a tentação de crer que os filhos dos agricultores não assumem a atividade familiar só por razões essencialmente econômicas: para que um empreendimento seja assumido, bastaria que fosse economicamente rentável. Como, então, explicar que alguns empreendimentos que não são considerados 'rentáveis' pelos próprios agricultores, tenham, no entanto, um sucessor? (...) A preponderância indiscutível do fator econômico corre o risco, sabe-se, de ocultar fatores sociais que tornam possível a autonomia desta representação econômica da sucessão (CHAMPAGNE, 1986, p. 26).

Ao se apontar o entorno (a comunidade e a sociedade local) como fator decisivo nas ações e decisões que os produtores assumem nas formas de reprodução de sua unidade de produção familiar, observa-se que essa reprodução está relacionada também à identidade desse produtor.

(...) significa pertença de atores sociais a uma condição social em relação a outros atores e outras condições sociais. Essa pertença é definida pela concepção geral ou visão de mundo, pelo estilo de vida, pelas relações com os outros e com a natureza, pelo sistema de trabalho e de produção, pelo espírito religioso e pelo sistema de reprodução biológica e social (GEHLEN, 1998, p. 56). 
De acordo com a Embrapa (2005), os pecuaristas familiares representam uma fração importante da população rural da região da Campanha Gaúcha. Hoje, eles são reconhecidos pelos agentes da extensão oficial, com suas demandas tecnológicas centrando-se na busca de animais adequados às condições de criação, melhoria do controle de enfermidades parasitárias e novas alternativas forrageiras para alimentação animal. No aspecto de infraestrutura, as principais demandas se concentram em questões de saúde, energia elétrica e transporte.

Ainda segundo a Embrapa (2005), a identificação do crescimento em importância de uma nova tendência tem sido a abordagem territorial no desenho de novos formatos tecnológicos. Concomitante a isso, a parece uma forte tendência de ampliação da base social demandante de tecnologias de produção agropecuária, com a maior participação organizada de outras categorias sociais, como a pecuária familiar. São condicionantes importantes que levam a considerar a necessidade de se produzir tecnologias apropriadas às diferentes condições socioculturais, econômicas e ecológicas pertinentes a cada categoria, seja do agronegócio, seja da agropecuária familiar, que englobam uma diversidade de produtores.

\section{Método}

No arcabouço deste trabalho, aparecem elementos identificados com os pressupostos definidos por Minayo et al. (1994) do que é pesquisa:

...é a atividade básica da ciência na sua indagação e construção da realidade.

É a pesquisa que alimenta as atividades de ensino e a atualiza frente à realidade do mundo. Portanto, embora seja uma prática teórica, a pesquisa vincula pensamento e ação. [...] As questões da investigação estão, portanto, relacionadas a interesses e circunstâncias socialmente condicionadas. São fruto de determinada inserção no real, nele encontrando suas razões e objetivos (MINAYO et al., 1994).

O estudo foi realizado a campo a partir de uma pesquisa exploratóriodescritiva por amostragem, com variáveis quantitativas e qualitativas. Utilizouse a técnica da entrevista estruturada por meio de aplicação de questionário fechado. De acordo com Gil (1999), esse tipo de entrevista se dá a partir de uma relação fixa de perguntas e de ordem invariável para todos os entrevistados, possibilitando a análise estatística dos dados, já que as respostas obtidas são padronizadas.

O projeto piloto (pré-entrevista), na fase de testes, foi aplicado a um número reduzido de pessoas ligadas à área acadêmica e de instituições de pesquisa que apresentam conhecimento de causa. $\mathrm{O}$ intuito era analisar determinados erros

8 Minayo et al. (1994) apud Bezerra (2006, p. 38). 
ou expressões dúbias, para que o questionário fosse aplicado sem problemas de interpretação.

$\mathrm{Na}$ fase de levantamento de dados, particularmente no que diz respeito à aplicação dos questionários, optou-se por um processo de amostragem que assegurasse a representatividade das unidades de produção de pecuária familiar, de forma a retratar, no estudo de caso, a realidade do segmento social no campo. Segundo Yin (2001), o estudo de caso é uma forma estratégica de pesquisa intensiva, em que se considera, principalmente, a descrição e a compreensão de fenômenos sociais complexos, através das relações dos fatores em um contexto social selecionado. No estudo de caso, tem-se a capacidade de lidar com uma ampla variedade de evidências - documentos, artefatos, entrevistas e observações -, além do disponível no estudo histórico convencional.

Segundo a Prefeitura Municipal de Bagé (2007), o município responde por um contingente de aproximadamente 2.000 unidades de produção rural, sendo 1.400 consideradas de caráter familiar. Com base nesses dados, conforme a Emater Municipal (escritório de Bagé), a Inspetoria Veterinária do estado do RS (escritório local) e a Secretaria Municipal de Desenvolvimento Econômico - Coordenadoria Agropecuária - da Prefeitura de Bagé, em 2006, o número de unidades de produção de caráter familiar dedicadas à produção de animais totalizava $400(\mathrm{~N}=400)$. Desse total, 10\% ou 40 unidades compuseram a amostra. Por fim, buscou-se junto a esses órgãos, a indicação das unidades mais representativas que serviriam de base para a aplicação deste trabalho de pesquisa, de forma a retratar a realidade da pecuária familiar.

Na Figura 2, nota-se predominância das áreas de pecuária familiar pela região da Campanha Gaúcha e, no detalhe, aquelas referentes ao município de Bagé.

Figura 2. Áreas de pecuária familiar no município de Bagé (RS)
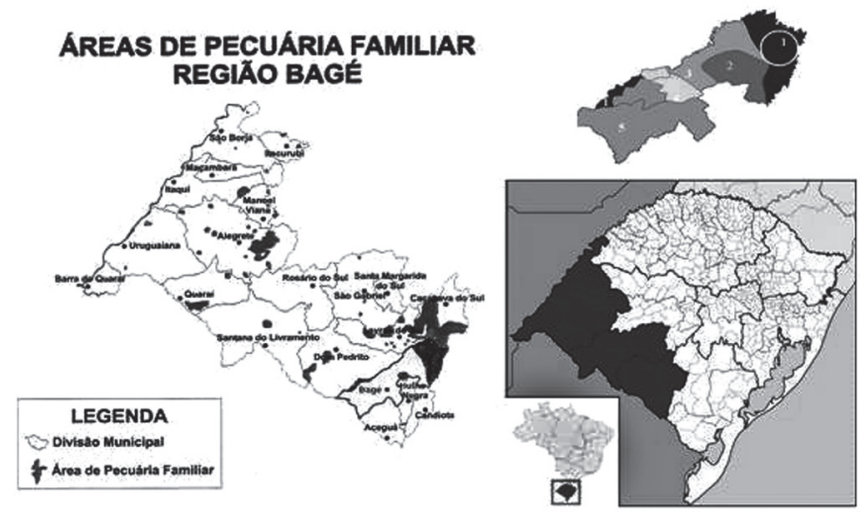

Fonte: elaborada pelo autor (2009). 
Após a coleta dos dados, passou-se para a etapa de processamento no software Statistical Package for the Social Science (SPSS ${ }^{\circledR}$ versão 12.0), para se proceder à leitura estatística e, dentro das possibilidades, realizar a análise de clusters ou conglomerados. Esse software é uma ferramenta para análise multivariada, a qual qualifica os resultados do trabalho de pesquisa. Segundo Everitt (1993) e Manly (1986), a análise de cluster é uma técnica estatística que objetiva agrupar os indivíduos (casos) com características semelhantes em função de um conjunto de variáveis selecionadas. Assim, a análise de cluster classifica os indivíduos (casos) em grupos homogêneos, denominados clusters ou conglomerados. No entanto, em função de outros fatores e condicionantes, foi possível realizar somente a distribuição de frequência e porcentagem dos dados por meio da análise estatística pelo SPSS.

As localidades abrangidas no estudo, conforme a Tabela 1, foram determinadas e distribuídas de forma proporcional às suas representatividades em termos quantitativos do universo da pecuária familiar.

Tabela 1. Distribuição dos questionários por localidades rurais no município de Bagé (RS)

\begin{tabular}{lcc}
\hline \multicolumn{1}{c}{ Localidades } & Porcentagem $\mathbf{( \% )}$ & Frequência \\
\hline Pedra Grande - Palmas & 30,0 & 12 \\
Coxilha das Flores - Palmas & 25,0 & 10 \\
Catarina - Palmas & 5,0 & 2 \\
Toca - Palmas & 5,0 & 2 \\
Lixiguana - Palmas & 2,5 & 1 \\
Olhos D'Água & 15 & 6 \\
Coxilha do Haedo & 10,0 & 4 \\
Santa Tecla - Bagé & 5,0 & 2 \\
Serrilhada & 2,5 & 1 \\
Total & 100,0 & 40 \\
\hline
\end{tabular}

Fonte: Trabalho de campo, 2007.

\section{Resultados e Discussão}

Em relação à estrutura fundiária, a Tabela 2 mostra que a maioria das unidades de produção $(80 \%)$ encontra-se numa faixa cujo limite superior é 200 hectares. Isso indica que, em termos de área, a pecuária familiar é constituída por unidades rurais relativamente pequenas diante do caráter extensivo da produção animal. Além disso, tal produção se desenvolve em ambientes considerados frágeis do ponto de vista da potencialidade agronômica das áreas, ou seja, de baixa superfície agrícola útil (SAU). 
Segundo a Emater/RS (2003), embora existam grandes unidades de produção na região da Campanha Gaúcha, as mudanças históricas provocaram a formação de um contingente de produtores rurais que, apesar de possuírem áreas menores, continuaram com a pecuária de corte como sua principal atividade produtiva. Esses produtores, mesmo pouco reconhecidos, são numerosos e se constituem em importante categoria social do campo. Apesar dos conceitos e preconceitos existentes quanto à região da Campanha do RS - de que nela existam apenas grandes unidades de produção -, aquelas com até 100 hectares representam a maioria (cerca de $70 \%$ ) do total de unidades produtivas da região, incluindose Bagé, sendo em grande parte compostas por pecuaristas. Obviamente que se deve ressaltar que o objeto de estudo e, consequentemente, as áreas rurais abrangidas no trabalho recaíram sobre a pecuária familiar, mas, mesmo assim, pode-se demonstrar, com isso, a importância das unidades de menor porte para o desenvolvimento social e econômico do município e região.

Tabela 2. Distribuição da estrutura fundiária nas unidades de produção selecionadas no município de Bagé (RS)

\begin{tabular}{lcc}
\hline \multicolumn{1}{c}{ Estratos de área (Ha) } & Porcentagem $\mathbf{( \% )}$ & Frequência \\
\hline $0-50$ & 32,5 & 13 \\
$50-100$ & 25,0 & 10 \\
$100-200$ & 22,5 & 9 \\
$200-300$ & 12,5 & 5 \\
Acima de 300 & 7,5 & 3 \\
Total & 100,0 & 40 \\
\hline
\end{tabular}

Fonte: Trabalho de campo, 2007.

Ainda de acordo com a Emater/RS (2003), a maioria dos municípios da região da Campanha apresenta um alto índice de unidades de produção com até 200 hectares. Com exceção de Uruguaiana, onde o percentual das unidades de produção com menos de 200 hectares é de $49 \%$, todos os demais municípios da Campanha Gaúcha registram percentuais superiores a 64\%. Portanto, ao contrário do que se afirma, não existem somente grandes unidades, mas, sim, um grande número de unidades de produção com limitada área física, inclusive, quando se trata da pecuária.

A pecuária familiar, na maioria dos casos, encontra-se entremeada às unidades de produção maiores, próximas ao que se denomina de estâncias e distribuídas em todos os municípios da Campanha. Essa é uma característica da região que acaba dificultando a identificação da categoria social, de modo a não se dar tanta importância à mesma e/ou não reconhecer sua existência. Entretanto, grande parte dos produtores vive em unidades de produção constituídas de 
pouca dimensão física (terra), utiliza mão de obra essencialmente familiar e tem na pecuária de corte uma fração de sua fonte de renda. Ainda assim, essas localidades identificadas apresentam diferenças entre si, ou seja, as variações ambientais fazem com que existam tipos distintos de pecuaristas familiares. As lógicas de produção e a base das atividades produtivas são similares, porém os recursos, as produções, os aspectos de comercialização, o acesso às informações, bem como os anseios e expectativas variam.

No tocante à modalidade de exploração das unidades de produção, nota-se que $85 \%$ dos produtores são proprietários das áreas, sendo este um dos aspectos que caracteriza a agricultura familiar e, consequentemente, a pecuária familiar, visto que a transmissão intergeracional do patrimônio se dá no interior da família (Tabela 3).

Tabela 3. Modalidade de exploração nas unidades de produção selecionadas no município de Bagé (RS).

\begin{tabular}{lcc}
\hline Modalidade de exploração & Porcentagem $\mathbf{( \% )}$ & Frequência \\
\hline Parceria & 10,0 & 4 \\
Arrendamento & 5,0 & 2 \\
Proprietário & 85,0 & 34 \\
Total & 100,0 & 40 \\
\hline
\end{tabular}

Fonte: Trabalho de campo, 2007.

Quanto à natureza do trabalho, na maioria dos casos $(87,5 \%)$, o emprego da mão de obra se baseia, essencialmente, no caráter familiar, confirmando a base teórica que alude ao fato de que a pecuária familiar seria um tipo específico de agricultura familiar (Tabela 4).

Tabela 4. Natureza do trabalho nas unidades de produção selecionadas no município de Bagé (RS).

\begin{tabular}{lcc}
\hline \multicolumn{1}{c}{ Natureza do trabalho } & Porcentagem $(\%)$ & Frequência \\
\hline Familiar & 87,5 & 35 \\
Familiar e Contratada & 12,5 & 5 \\
Total & 100,0 & 40 \\
\hline
\end{tabular}

Fonte: Trabalho de campo, 2007.

A principal tarefa familiar está relacionada à manutenção do sistema produtivo como um todo (entradas e saídas, lida diária no campo e necessidades da família), enquanto a mão de obra contratada dedica-se a tarefas estritamente voltadas à atividade produtiva agrícola. 
Quando questionados sobre o principal objetivo econômico da produção pecuária, $85 \%$ dos produtores responderam "gado de cria" (produção de terneiros), conforme mostra a Tabela 5. Sabe-se que a pecuária de gado de corte é um sistema de produção composto por etapas sequenciais interdependentes (cria, recria e engorda), as quais exigem manejos diferenciados. Tais etapas podem ser realizadas todas na mesma unidade de produção (integração horizontal) ou separadamente, o que garante maior especialização em uma dessas etapas. No caso dos pecuaristas familiares, a maioria se move até o mercado, procurando o maior retorno de seu produto, ou seja, a tendência tem sido pela valorização do terneiro em termos de valor pago.

Tabela 5. Objetivo econômico da produção nas unidades de produção selecionadas no município de Bagé (RS).

\begin{tabular}{lcc}
\hline Objetivo econômico & Porcentagem $\mathbf{( \% )}$ & Frequência \\
\hline Cria & 85,0 & 34 \\
Recria & 2,5 & 1 \\
Cria + Recria & 10,0 & 4 \\
Ciclo completo & 2,5 & 1 \\
Total & 100,0 & 40 \\
\hline
\end{tabular}

Fonte: Trabalho de campo, 2007.

Quanto ao formato de comercialização da produção (Tabela 6), 95\% dos entrevistados disseram vender seu produto ao intermediário 9 . Na sequência, na pergunta referente aos tipos de intermediários, observa-se que o produtor que realiza a terminação do gado de corte (invernador) é o principal intermediário envolvido no processo de venda e que acaba absorvendo uma parte substancial da produção da pecuária familiar (Tabela 7).

Tabela 6. Forma de comercialização nas unidades de produção selecionadas no município de Bagé (RS).

\begin{tabular}{lcc}
\hline \multicolumn{1}{c}{ Comercialização } & Porcentagem (\%) & Frequência \\
\hline Venda ao intermediário & 95,0 & 38 \\
Venda ao frigorífico/abatedouro & 2,5 & 1 \\
Venda ao intermediário + frigorífico/abatedouro & 2,5 & 1 \\
Total & 100,0 & 40 \\
\hline
\end{tabular}

Fonte: Trabalho de campo, 2007.

9 Considera-se, para fins deste artigo, intermediário como sendo aquela forma de comercialização de gado realizada segundo o ciclo da produção pecuária (cria, recria e terminação) - a transação comercial se dá entre uma dessas etapas sequenciais da atividade produtiva em relação ao destino final do produto. Neste trabalho, observa-se a predominância da venda de terneiros para outros produtores (invernadores) como a principal forma de comercialização por parte dos pecuaristas familiares. 
Tabela 7. Intermediários na comercialização nas unidades de produção selecionadas no município de Bagé (RS)

\begin{tabular}{lcc}
\hline \multicolumn{1}{c}{ Intermediários } & Porcentagem $\mathbf{( \% )}$ & Frequência \\
\hline Produtor (invernador) & 82,5 & 33 \\
Escritório de vendas & 7,5 & 3 \\
Misto (produtor + feiras/remates) & 5,0 & 2 \\
Feiras e remates & 2,5 & 1 \\
Não se aplica & 2,5 & 1 \\
Total & 100,0 & 40 \\
\hline
\end{tabular}

Fonte: Trabalho de campo, 2007.

A Tabela 8 dá conta acerca da integração às cadeias produtivas por parte da pecuária familiar em termos do processo de verticalização da produção (via contratos formais) com empresas do setor (frigoríficos e abatedouros). Verificase que, em nenhum dos casos, foi observada essa aderência, o que pode ser explicado por dois motivos principais: a) pela pequena escala de produção da pecuária familiar, a qual não atenderia a cadeia produtiva em termos de abastecimento de carne; e $b$ ) em função da lógica familiar de produção considerar o bovino tanto bem de capital quanto bem de consumo, haveria uma relação de assimetria comercial entre a pecuária familiar e o mercado - haja vista que o pecuarista só se move até este mercado quando lhe é favorável e conveniente, segundo suas aspirações e necessidades, pois, pela lógica de produção da pecuária familiar, esta não atende única e exclusivamente o lucro.

Tabela 8. Integração da produção nas unidades de produção selecionadas no município de Bagé (RS)

\begin{tabular}{lcc}
\hline Integração ao mercado & Porcentagem $(\boldsymbol{\%})$ & Frequência \\
\hline Sim & 0,0 & 0 \\
Não & 100,0 & 40 \\
Total & 100,0 & 40 \\
\hline
\end{tabular}

Fonte: Trabalho de campo, 2007.

Pela Tabela 9, observa-se que a maioria dos pecuaristas familiares $(70 \%)$ aufere renda agrícola inferior a dois salários mínimos, o que não caracteriza margem elevada segundo a ideia estereotipada que se tem de quem trabalha com pecuária de corte. Esse dado é de fundamental importância, na medida em que reflete o entendimento acerca das reais condições socioeconômicas das famílias. Além disso, cabe destacar que, quando se fala em agricultura familiar - no presente trabalho, em pecuária familiar enquanto forma social 
de produção -, deve-se atentar às diversas dimensões que a atividade encerra em sua lógica peculiar de funcionamento, nomeadamente a econômica no aspecto renda. Assim, pode-se perceber que a atividade pecuária (bovinos de corte) não apresenta ingresso de renda agrícola durante todos os meses do ano, principalmente no caso da pecuária familiar, que, de forma geral, se caracteriza por uma pequena produção em termos de rebanho por produtor.

Tabela 9. Renda agrícola nas unidades de produção selecionadas no município de Bagé (RS)

\begin{tabular}{lcc}
\hline \multicolumn{1}{c}{$\begin{array}{c}\text { Renda agrícola } \\
\text { (em salários mínimos) }\end{array}$} & Porcentagem $\mathbf{( \% )}$ & Frequência \\
\hline Menos de 2 & 70,0 & 28 \\
2 a 5 & 20,0 & 8 \\
6 a 10 & 10,0 & 4 \\
Total & 100,0 & 40 \\
\hline
\end{tabular}

Fonte: Trabalho de campo, 2007.

Na Tabela 10, nota-se a fundamental importância das atividades e rendas não-agrícolas. A aposentadoria rural figura em $41,9 \%$ dos casos verificados, seguida de rendas não-agrícolas de outra natureza, que aparecem no âmbito da realidade investigada, como é o caso de funcionários públicos, prestadores de serviços e outras combinações bastante diversificadas. É com base nessas fontes de ingresso que muitos pecuaristas familiares conseguem viabilizar a atividade produtiva e a reprodução social de suas famílias. Vale destacar que, no aspecto das rendas não-agrícolas, somente nove produtores não registraram fontes de ingresso dessa natureza, ou seja, da amostra de 40 produtores, 31 apresentaram rendas não-agrícolas como importante fonte de renda complementar.

Esse quadro exprime a busca recorrente das famílias por alternativas de renda que complementem a vulnerabilidade à qual permanentemente achamse expostas no contexto de uma atividade refém das oscilações dos mercados e de problemas ambientais e sanitários - caso das últimas secas que atingiram a região e das doenças recorrentes dos rebanhos bovinos (aftosa, brucelose, etc.), respectivamente.

Verificou-se, ainda, que, em alguns casos, a renda obtida a partir de outras atividades supera a agrícola. De qualquer foram, esse valor é gerenciado pelo chefe da família, que o destina à manutenção das atividades produtivas. A venda de mão de obra, característica desses produtores, representa, muitas vezes, uma remuneração temporária, de modo que esses pecuaristas acabam investindo pouco na própria unidade em termos de infraestrutura e, consequentemente, em tecnologia de produção. Na lógica desses agentes, os recursos advindos da pecuária de corte são "como uma poupança", sendo utilizados em momentos de necessidade para cobrir despesas não previstas e extraordinárias da família. 
Tabela 10. Renda não-agrícola nas unidades de produção selecionadas no município de Bagé (RS)

\begin{tabular}{lcc}
\hline \multicolumn{1}{c}{ Renda não-agrícola } & $\begin{array}{c}\text { Porcentagem } \\
(\boldsymbol{\%})\end{array}$ & Frequência \\
\hline Aposentadoria rural & 41,9 & 13 \\
Serviços (aramador, changueador) & 19,4 & 6 \\
Funcionário público (professor, técnico, agente de saúde) & 9,8 & 3 \\
Assalariado (empregado rural, terceirizados) & 6,4 & 2 \\
Autônomo (mecânico, veterinário, inseminador, comerciante) & 6,4 & 2 \\
Mista (aposentadoria mais outras rendas não-agrícolas) & 6,4 & 2 \\
Diversa* (combinação de duas ou mais rendas não-agrícolas) & 6,4 & 2 \\
Artesão & 3,3 & 1 \\
Total & 100,0 & 31 \\
Não se aplica & 100,0 & 9 \\
Total & 100,00 & 40 \\
\hline
\end{tabular}

* Combinação de duas ou mais rendas não-agrícolas, excetuando-se a aposentadoria rural, sendo que esta última já figura no tipo "Mista" da Tabela 10.

Fonte: Trabalho de campo, 2007.

\section{Conclusões}

O que se pode apreender deste trabalho é uma contribuição para o entendimento da lógica da pecuária familiar enquanto uma especificidade da agricultura familiar, além da identificação de elementos característicos dessa categoria social presente no município de Bagé, localizado na região da Campanha Meridional, no estado do Rio Grande do Sul.

A pecuária familiar foi identificada como um tipo de agricultura familiar diferenciada, com características internas próprias que lhe conferem uma diversidade de sistemas e de produtores. No entanto, pode-se afirmar que a pecuária familiar apresenta elementos fundamentais que é comum a esses diversos sistemas e produtores, sendo que essa categoria social se mostra aderente ao conceito maior de agricultura familiar.

Sendo assim, os principais aspectos da pecuária familiar em Bagé (RS) são: (a) a atividade produtiva mais representativa é a bovinocultura de corte, constatando-se a identidade cultural de "pecuaristas", de pessoas ligadas ao gado como atividade que lhes dá segurança - o mesmo gado é visto como mercadoria de reserva e comercializado de acordo com as necessidades, expectativas e desejos da família; (b) a mão de obra é predominantemente familiar, havendo também troca de serviços entre os produtores (vizinhos e 
parentes) em determinadas épocas; (c) a pecuária de corte ocupa a maior parte da área das unidades de produção, embora não responda pela maior fonte de renda dos produtores, e a estrutura fundiária se limita a 200 hectares; (d) possui renda agrícola de até dois salários mínimos; e (e) tem na aposentadoria rural sua principal fonte de renda não-agrícola, a qual é bastante representativa na renda total para gastos em geral e manutenção da atividade produtiva.

Por fim, reafirma-se que a pecuária familiar, enquanto categoria social produtiva, é uma forma específica de manifestação da agricultura familiar. Apresenta relevante importância socioeconômica e ambiental para a região gaúcha, sendo fundamental para a manutenção dos produtores e suas famílias no campo, e contribuindo significativamente com a produção pecuária e, consequentemente, com a produção de alimentos.

\section{Referências Bibliográficas}

ASSOCIAÇÃO RIOGRANDENSE DE EMPREENDIMENTOS, ASSISTÊNCIA TÉCNICA E EXTENSÃO RURAL (EMATER/RS) - ASSOCIAÇÃO SULINA DE CRÉDITO E ASSISTÊNCIA RURAL (ASCAR). Disponível em: <http://www. emater.tche.br/site/inicial/ptbr/pho/> Acesso em: 23 nov. 2006.

ASSOCIAÇÃO RIOGRANDENSE DE EMPREENDIMENTOS, ASSISTÊNCIA TÉCNICA E EXTENSÃO RURAL (EMATER/RS) - ASSOCIAÇÃO SULINA DE CRÉDITO E ASSISTÊNCIA RURAL (ASCAR). Pecuária familiar. Porto Alegre, 2003. 78p. (Série Realidade Rural, 34).

ASSOCIAÇÃO RIOGRANDENSE DE EMPREENDIMENTOS, ASSISTÊNCIA TÉCNICA E EXTENSÃO RURAL (EMATER/RS) - ASSOCIAÇÃO SULINA DE CRÉDITO E ASSISTÊNCIA RURAL (ASCAR). Escritório Municipal de Bagé. Relatório anual de ações e resultados. 2006.

BEZERRA, A. J. A. A agricultura familiar e a universalização dos direitos sociais: estudo sobre a previdência social rural no município de Morro Redondo, Rio Grande do Sul. 2006. 139 f. Tese (Doutorado em Produção Vegetal) - Programa de Pós-Graduação em Agronomia, Universidade Federal de Pelotas, Pelotas, 2006.

BRASIL. Instituto Brasileiro de Geografia e Estatística - IBGE. População, Economia e Canais (Banco de Dados). Disponível em: <http://www.ibge.gov.br/home/>. Acesso em: 10 set. 2007.

CHAMPAGNE, P. A reprodução da identidade. Paris - Dijon, INRA, 1986. 2 Vols., p. 185 e 165.

CHAYANOV, A. V. Sobre a teoria dos sistemas econômicos não capitalistas. In: SILVA, J. G.; STOLCKE, V. A questão agrária. São Paulo: Brasiliense, 1981. p. 133163. 
CHAYANOV, A. V. La organización de la unidad económica campesina. Buenos Aires: Nueva Visión, 1974. 194 p.

EMPRESA BRASILEIRA DE PESQUISA AGROPECUÁRIA (EMBRAPA). Pesquisa visa fortalecer elo fraco da cadeia produtiva. In: Folha do Produtor. Bagé: Embrapa Pecuária Sul, Ano 16, no 20, 2005. p. 7.

EMPRESA BRASILEIRA DE PESQUISA AGROPECUÁRIA (EMBRAPA). EMBRAPA PECUÁRIA SUL. III Plano Diretor da Embrapa Pecuária Sul: 2004-2007. Bagé, 2005. 38p. (Embrapa, Documentos 59).

ESTADO DO RIO GRANDE DO SUL. Secretaria da Agricultura, Pecuária e Agronegócio. Disponível em: <http://www.saa.rs.gov.br> Acesso em 15 nov. 2006.

ESTADO DO RIO GRANDE DO SUL. Secretaria do Planejamento e Gestão. Atlas Socioeconômico do Rio Grande do Sul. Disponível em: http://www.scp.rs.gov. br/atlas. Acesso em: 13 out. 2006.

EVERITT, B. S. Cluster analysis. London: Hodder \& Stoughton, 1993. 170 p.

FAO/INCRA. Perfil da agricultura familiar no Brasil: dossiê estatístico. 1996. Brasília. In: GUANZIROLI, C.; CARDIM, S. (coord.). O novo retrato da agricultura familiar: o Brasil Redescoberto. 2000. Brasília, Convênio FAO/Incra, INCRA.

GEHLEN, I. Para pensar outra agricultura. Coletânea de artigos/organizadores: Ângela Duarte Damasceno, Alfio Brandenburg. Curitiba: Ed. UFPR, 1998. 275 p.

GIL, A. C. Métodos e técnicas de pesquisa social. 5a edição. São Paulo: Atlas, 1999. $206 \mathrm{p}$.

KAUTSKY, K. A questão agrária. Brasília: Linha Gráfica, 1998. 586 p.

LAMARCHE, H. (coord.). Agricultura familiar: comparação internacional - uma realidade multiforme. Vol. 1. Campinas: Ed. UNICAMP, 1993. 336 p.

MANLY, B. F. J. Multivariate statistical methods: a primer. London: Chapman \& Hall, 1986. 159 p.

MIELITZ NETTO, C. G. A. Modernização e diferenciação na bovinocultura de corte brasileira. 1994. 224 f. Tese (Doutorado em Economia) - Instituto de Economia, Universidade Estadual de Campinas, Campinas, 1994.

MIGUEL, L.A.; MIELITZ NETTO, C. G. A.; NABINGER, C.; SANGUINÉ, E.; WAQUIL, P. D.; SCHNEIDER, S. Caracterização socioeconômica e produtiva da bovinocultura de corte no Estado do Rio Grande do Sul. Disponível em: < http://www. pucrs.br/eventos/3eeg/Artigos/m02t03.pdf> Acesso em: 31 out. 2006. 
PLOEG, J. D. van der. El proceso de trabajo agrícola y la mercantilización. In: GUZMÁN, E. S. (Ed.). Ecologia, campesinado y historia. Espana: Lãs Ediciones de la Piqueta, 1992.

PREFEITURA MUNICIPAL DE BAGÉ. História, dados e economia. Disponível em: <http://www.bage.rs.gov.br> Acesso em: 02 ago. 2007.

SACCO DOS ANJOS, F. Agricultura familiar, pluriatividade e desenvolvimento rural no sul do Brasil. Pelotas: EGUFPEL, 2003. 374 p.

SANDRINI, G. B. D. Processo de inserção dos pecuaristas familiares do Rio Grande do Sul na cadeia produtiva da carne. 2005. 179 f. Dissertação (Mestrado em Desenvolvimento Rural) - Programa de Pós-Graduação em Desenvolvimento Rural, Universidade Federal do Rio Grande do Sul, Porto Alegre, 2005.

SEBRAE/FARSUL/SENAR. Diagnóstico de sistemas de produção da bovinocultura de corte do Estado do Rio Grande do Sul. Relatório de Pesquisa, IEPE/UFRGS. Porto Alegre, 2005. $265 \mathrm{p}$.

WANDERLEY, M. N. B. Raizes do campesinato brasileiro. In: Tedesco, J. C. Agricultura familiar: realidades e perspectivas. Passo Fundo: EDIUPF, 1999. (Capítulo 1, p.23-56)

YIN, R. K. Estudo de caso: planejamento e métodos. Porto Alegre: Ed. Bookman, 2001. 205 p. 